\title{
The Philosophical Significance of a Shared Language
}

\author{
Andreas KemmerLing
}

Basically, I shall be arguing for two things in this paper. First, that Davidson's account of linguistic communication fails to account for certain cases and distinctions which make an essential difference according to our intuitive ways of viewing these matters. Second, that any account of the objectivity of belief-attributions should involve the idea of a shared language - even if this idea (or ideal) may pop up only in the background of such an account.

In the first six sections of the paper, I shall try to describe Davidson's views on literal meaning (in linguistic communication), as sympathetically as I can. In section VII, I adduce some of my reasons for taking these views to be unsatisfactory.

In the second part of the paper, i. e. from section VIII on, I will argue that it takes a shared language to allow for the objectivity of beliefattributions. In this part of the paper, I shall not be concerned primarily with an exegesis of Davidson's writings. I want to point out, in this second part, that Davidson's approach to the theory of meaning - given a realist and objectivist rendering of at least some outstandingly uncontroversial belief-attributions - presupposes the concept of a shared language. Objectivity in interpretation presupposes a language shared between the interpreter and his potential critics (his critical peers), even if it does not presuppose a language shared between the interpreter and his interpretandus.

I.

Professor Davidson has recently expressed reservations about there being something which this paper's title refers to although he seems not to want to go so far as to deny the existence of shared languages. But he does seem to be prepared to deny that the existence of such languages is a fact of prominent importance within the context of philosophical reflection on successful linguistic communication. In his essay entitled "Communication 
and Convention", he attacks the idea that convention helps to explain what is basic to linguistic communication. ${ }^{1}$ At the end of his contribution to the Grice-festschrift, Davidson concludes that "there is no such thing as a language, not if language is anything like what many philosophers and linguists have supposed." 2 And in the second part of his lectures on "The Structure and Content of Truth" he says:

The approach $I$ am following puts no primary weight on the concept of a language as something shared by speaker and interpreter, or by a speaker and a speech community, except in this sense: though communication by speech does not, as far as I can see, tequire that any two speakers speak in the same way, it does, of course, demand a fit between how speakers intend to be interpreted and how their interpreters understand them. This demand no doubt tends to encourage convergence in speech behavior among those who exchange words, the degree depending on factors like shared social and economic status, educational and ethnic background, etc. What convergence exists is of such vast practical importance that we may exaggerate both its degree and its philosophical significance. But $I$ think we do well to ignore this practical issue in constructing theories of meaning, of truth, and of linguistic communication. I shall therefore treat theories of truth as applicable in the first place to individual speakers at various periods or even moments of their lives. ${ }^{3}$

Could there be a group of speaker/hearers such that each member of the group speaks a different language, yet, at the same time all of them are able to interpret one another appropriately? Certainly, such a thing seems possible. Take, for example, a group of Swiss people who happen to be travelling in the same train-compartment. They are having a conversation. The first one speaks Italian, the second French and the third Swiss German (Schwyzerdütsch). Their linguistic exchange may be as successful as that of identical American twins who have stuck together each minute of their lives, and hence have received exactly the same linguistic education, watched the same TV shows and what have you. So it seems that Davidson must be right; successful linguistic communication does not entail that the same language is spoken by those who communicate.

But don't our three Swiss travellers share a language? Don't they, in fact, share three languages? As I have just sketched the story, I think one should indeed say that they do. For each traveller is a competent hearer of Italian, French and Swiss German. If we assume (or naturally stipulate) that all competent hearers of a language share that language, then the travellers share three languages. They don't speak the same language. Yet they may share a language or even share several languages.

1. Inquiries into Truth and Interpretation, Oxford 1984, p. 280.

2 Cf. "A Nice Derangement of Epitaphs", in: Richard E. Grandy/Richard Warner (eds.), Pbilosophical Grounds of Rationality: Intentions, Categories, Ends, Oxford: Clarendon Press 1986, p. 174.

3 Journal of Philosopby 87 (1990), p. 311. 
II.

What is at issue in Professor Davidson's arguments clearly is the more controversial claim that linguistic communication can be successful without there being a language which is shared by those who communicate by using language. Prima facie, this claim looks like the denial of a platitude. The platitude in question may be decomposed into the following sequence of seemingly banal statements: Linguistic communication is communication by linguistic means. Linguistic means are means provided by a language. Successful communication entails understanding: that which is meant by the vehicle of communication must be that which is understood. Consequently, in successful linguistic communication, the means provided by a language are meant and understood in the same way. If the means provided by a language are meant and understood in the same way, this language is shared between the parties involved. End of the series. Upshot: If linguistic communication is successful, then a shared language is involved.

Let us try to get clearer about these issues by turning to a flow chartlike description of the account of linguistic communication I have just very loosely described. There is a speaker, $\mathrm{S}$, and somebody else we might call $\mathrm{H}$. S wants to communicate to $\mathrm{H}$ a particular message - e.g. the message that $\mathrm{p}$. This makes $\mathrm{H}$ the (intended) audience or the addressee. The speaker searches for a sentence which is true if and only if p. Eventually he utters a sentence of a certain language $\mathrm{L}$, and he utters this sentence as one of $\mathrm{L} . \mathrm{H}$ hears the utterance, that makes him a bearer. He recognizes it as the utterance of a sentence of language $\mathrm{L}$, that makes him a recognizer of a language possibly spoken. He knows the meaning conventions of $\mathrm{L}$ and thereby recognizes that the sentence uttered in this context is true if and only if $\mathrm{p}$. That makes him a competent L-hearer. He excludes, dismisses or ignores the possibility that the speaker employed a language different from L. So he recognizes that the speaker uttered the sentence as one of $\mathrm{L}$, and that makes the hearer a recognizer of the language actually spoken. He moreover excludes, dismisses or ignores possibilities like the following: that the speaker is just making a joke, that the speaker is just rehearsing for an audition, that the speaker is just trying to shed a colourful light on his state of mind - and indefinitely many other such possibilities. In excluding all such possibilities, he turns into a literal-taker. As a literal-taker, he equates the truth condition of the utterance with the message communicated; so he concludes that the speaker wants to communicate that p; and that makes him an understander.

That's, in rough outline, the story of successful linguistic communication. as it is only rarely explicitly stated but, I venture, much more often implicitly believed. Twenty years ago, it seemed, to many, to be the great 
story to be told. There was, on the one hand (on the pragmatic side of meaning theory), the stimulating work of Grice and the brilliant additions to it by Lewis, Schiffer and Bennett. On the other hand - on the semantical side of meaning theory - there was Davidson for the extensionalists (philosophers, mainly) and Montague for the intensionalists (linguists, mainly). The Zeitgeist of the seventies was quite plain about meaning theory: Combine pragmatics à la Grice with semantics à la Davidson or Montague via an account of convention à la Lewis and you'll get a pretty good picture of what an account of successful linguistic communication should look like. The details of each of the three components were of course highly controversial (how to deal with non-assertoric language use? how to tone down the strong intellectualist flavour of Grice's and Lewis's model? how to include Donnellan's, Putnam's and Kripke's observations on the ways in which the referent of a linguistic term is fixed?) There were - and are - countless further fascinating questions for those who believed (and still believe) this framework to be basically on the right track.

Let us, for what follows, call this account of successful linguistic communication the standard account. It maintains (among other things) that semantics deals with literal meaning, that literal meaning is conventional meaning, that such meaning is shared in advance, and that it is in some sense obligatory for those who share that meaning to stick to it.

Professor Davidson finds at least two things wrong with the standard account. First, the idea that there is some comprehensive pre-established semantic harmony between speaker and hearer when linguistic communication takes place. Second, the idea that conventions significantly contribute to establishing such harmony. These two ideas are closely connected, yet they are different. The first idea can be turned into a more tangible claim: There is a truth theory (or some other kind of description of language $L$ ) which is, first, fit for interpreting the speaker and, secondly, fit for describing the tacit interpretive knowledge of the hearer; and some such truth theory is implicitly relied upon by both parties. The second idea involves a strengthening of the first claim with regard to the nature of the implicit reliance. It says that there is a convention between speaker and hearer to rely on the same truth theory, and there being such a convention is a conceptual ingredient of genuine linguistic communication. That is to say (among other things) that speaker and hearer do not achieve their communicative success by accidentally hitting upon the same truth theory on that occasion or by laboriously inventing one on the spot, but rather they appeared on the scene with an implicit agreement to apply the same truth theory. ${ }^{4}$

4 Of course, this phrase "implicit agreement to apply the same truth theory" is ambiguous. It may mean, first, that there is a particular truth theory, $\Theta$, and what the implicit agreement comes to is this: Let's apply $\Theta$ ! And it may mean, secondly, that the implicit 
Let me try to make this point about convention vivid: Imagine an infinite library in which all truth theories are kept, each in a separate volume. Two people who want to communicate linguistically have to pick one of those books and to swear that at their ensuing encounters they will take the truth theory contained in that book as their interpretational standard. (Please do not ask how they manage to swear this oath, I only promised to give you a vivid picture, not a picture without problems. ${ }^{5}$ ) Later on, they stick to their oath and rely on each other's doing so. And thereby they have established a convention, because they follow the rule to apply this one particular volume (let's say, it is entitled English), but they might as well have picked a different volume when they swore (e.g. the one entitled German). Therefore they follow a rule to which there is a rational alternative, and that is to say, they follow a convention.

So much about the standard account. Professor Davidson thinks that the whole part of the story which brings in the reliance on a shared language is conceptually superfluous and should be avoided in a philosophical account of linguistic communication. Not only does he find the special features of the library and the oath objectionable, but also the general idea that speaker and hearer should share a language.

Before I go on, let me get one topic out of the way. My discussion is not concerned with the issue of indeterminacy of meaning or inscrutability of reference. The picture of the standard account, as $I$ have drawn it, makes unduly strict requirements. Certainly, the two people in the library need not agree on the very same volume, it will do if they agree on the same shelf. Provided that the library is well run. A well run library of that kind groups together volumes on the same shelf only if it does not matter (for the communicative purposes of the visitors) if speaker and hearer later on apply different copies from the same shelf. For example, one may feel that it does not matter for communicative success whether

agreement is not about any truth theory in particular but says only: Whatever truth theory you and I apply, let's apply the same one!

This ambiguity is important. On the one reading, the standard account may be blatantly wrong, on the other, it may be a very useful idealization. Davidson, $I$ take it, construes the standard account in the first way, and I shall therefore, from now on, reserve the label "standard account" for a position which is committed to the strong claim that there is an implicit agreement to apply one particular predetermined truth theory.

I agree with Davidson that the standard account, in this reading, is not feasible. But adherents to the standard account who have committed themselves to this strict reading are hard to find. (David Lewis may be cited as an exception. He has committed himself to that reading in his book Convention [Cambridge, Mass. 1969, chapter 5]. Yet given his cooperation-dominated conception of convention, even he is committed only in letter and not so clearly in spirit.)

${ }_{5}$ But this problem can be solved, e.g. by accepting an account like David Lewis's in Convention (Cambridge, Mass. 1969, chapters 4 and 5). 
the entries for "dürr" and "hager" are swapped in two given truth theories which are applied in interpreting an average German speaker. Here is another example. It does not matter at all if I grasp a volume which constantly delivers truth conditions like the one "that Harvey's center is the center of a crazy guy", even if my co-visitor has got hold of a volume which for the same occasions yields simpler results such as "that Harvey is a crazy guy". If I were to run such a library, I should put those volumes on the same shelf. Anyway, all this is not our immediate concern. When I speak of the same language or the same truth theory, I mean to be understood as suppressing, for the sake of brevity, the tag "modulo communicative equivalence". This manouevre of avoiding issues of indeterminacy may seem dubious. And certainly, the concept of communicative equivalence is far from clear. But here it is used simply as a coarse broom which comes handy in order to sweep aside undesired side issues.

III.

The real issues emerge when we turn to cases which Professor Davidson discusses in his paper "A Nice Derangement of Epitaphs". "Somebody says to me "Es ist möglich, daß es regnen wird, es ist aber auch nicht möglich". According to my book what he has said is true if and only if the following holds: it is possible that it is going to rain but it is also not possible. The standard account leaves me with several options. First option: I may try to understand the speaker's message as contradictory. Second, I can avoid turning into a literal-taker and assume instead that the speaker was joking or memorizing sentences from a course on modal logic he attended yesterday. Third, I may assume that the speaker is confused about which book he has sworn on. I may be left with a number of further options. But if I am faithful to my oath, there is no way for me to take the speaker both as speaking literally and as not conveying a contradictory message.

What I in fact do in such cases is simply this: I assume that the speaker has a somewhat different use of negation within modal constructions. Easily, and without feeling unfaithful, I interpret his message as being true if and only if it is possible that it's going to rain but also possible that it's not going to rain.

A sad fact about the standard account is that it fails to shed a light on this kind of successful linguistic communication. Even if it is possible, within the standard account, to exculpate me from the blame of semantic dishonesty, it does not seem possible, within this account, to explain how

${ }^{6}$ Cf. above, footnote 2 . 
I achieved understanding. Since such cases of successful linguistic communication are fairly common, we have to conclude at least that the standard account leaves out a wide range of data. The standard account, as it stands, fails to provide the explanatory tools needed for a common variety of cases of the phenomenon to be explained (in a philosophical sense of the phrase "to be explained"). Slips of the tongue, careless syntax, momentary or standing semantic confusions, use of expressions which have been mastered only partially, and more of such phenomena do not prevent us from linguistic understanding.

Professor Davidson takes this explanatory failure of the standard account to be revealing. If in such common cases the standard account yields no explanation for the success of linguistic communication, then we need an additional account anyway in order to explain that which has to be explained. But as soon as we get clear about what this additional account must look like, we find that we can generalize this theoretical addition and drop the standard account altogether. So we wind up with a different picture with a much greater applicability.

Let me try to describe this picture after introducing the required terminology. Linguistic communication is communication by linguistic means. Linguistic means are means provided by some language or other. Successful communication entails interpretation: in linguistic communication, linguistic means are meant and interpreted in the same way. Linguistic means may be meant and interpreted in the same way, although there is no language shared between the parties involved. Upshot: No language needs to be shared for linguistic communication to be successful. (All this sounds pretty similar to the standard account. The main change is that "interpretation" has been substituted for "understanding" and, of course, that the two upshots are incompatible.)

The flow chart like description pertaining to this picture goes as follows. Again, there is a speaker S and his intended audience, hearer H. Again, S wants to communicate to $H$ that $p$. $S$ has certain expectations about how $\mathrm{H}$ will interpret his utterances. Davidson calls the systematic rendering of the totality of these expectations the speaker's prior theory. ${ }^{7}$ So $\mathrm{S}$ searches for a sentence he expects $H$ to interpret (if uttered by him on the given occasion) as being true if and only if p. Eventually, he utters such a sentence, intending thereby that the utterance be intexpreted in that manner. $\mathrm{H}$ had entered the scene equipped with certain (tacit) expectations of what to make of indefinitely many sentences if they were uttered by the speaker on that occasion. The systematic rendering of these expectations Davidson calls the hearer's prior theory. And let us again concentrate on the case in which the hearer, on the occasion of the utterance, turns into a

7 Cf. "A Nice Derangement of Epitaphs", loc.cit. pp. $168 \mathrm{ff}$. 
literal-taker, i. e. he again excludes, dismisses or ignores the possibilities of non-literal language use on the speaker's part. The hearer's prior theory will then provide him with a first guess about what $S$ wants to communicate. Now our flow chart branches. There are two cases to be distinguished. In one of them, our hearer is satisfied with the outcome of this first guess; he checks the truth condition delivered by the prior theory against all of his relevant theory and evidence about the speaker's beliefs and desires, and it passes muster. If this is so, he will conclude that what the prior theory delivered is what $\mathrm{S}$ wanted to communicate. He will accept the result and stick to the prior theory.

In the second case, the hearer is not satisfied with the outcome. His prior theory delivers a truth condition which renders the speaker too clever or too stupid or much too something or other. The hearer finds: "Checked against my background assumptions, it is not plausible that $\mathrm{S}$ meant to communicate that so-and-so. This result refutes my prior theory". Off hand, he tries to improve his theory in order to come to grips with the speaker's utterance. He continues to stick to the assumption that he should interpret the speaker's utterance literally. If successful, he comes up with a new theory, specially designed for making optimal sense of this particular utterance. This Davidson calls the hearer's passing theory (of how to interpret that speaker on that occasion).

\section{IV.}

An Omissible Exegetical Insertion: The distinction between prior and passing theory has troubled people (me among them). So let me explain what I found difficult. My flow chart-like description of Davidson's nonstandard account of linguistic communication branches, on the hearer's side, as soon as the speaker's utterance comes into play. Before that, the hearer's prior theory represents his implicit knowledge of how to make sense of the speaker's utterances. The prior theory is tested by the speaker's utterance. If it fails the test, it is substituted by another theory, the passing theory. It is at this point, that my exegetical problem arises: If the prior theory passes the test, is it to be called, ipso facto, the passing theory, or is it still to be called the prior theory? Which of the following two analogies captures the point of the distinction better? The difference between one hammer which is held in preparation and a different hammer which is actually applied in driving the nail into the wall? Or the difference between a hammer, insofar as it is held in preparation, and a hammer, insofar as it actually does the job of driving the nail in? I take Professor Davidson to have the second distinction in mind. Accordingly, the prior theory and the passing theory can be identical in certain cases. So when Davidson 
says: "What must be shared for communication to succeed is the passing theory", 8 he does not, I take it, mean to deny that sharing the prior theory is sufficient for success of communication. So one better avoids speaking of "the passing theory" as opposed to speaking of "the prior theory". The theories referred to might, after all, be one and the same, viewed under different functional aspects. - End of the Omissible Exegetical Insertion.

V.

What Davidson's account comes to is this: ${ }^{9}$ An act of linguistic communication between $\mathrm{S}$ and $\mathrm{H}$ is successful if the hearer eventually arrives at a correct interpretation of the speaker's utterance. The hearer's interpretation is completely correct only if the following holds: the interpretation yields (1) what the speaker's words mean in his mouth on the occasion of the utterance, and (2) this result is arrived at by the hearer's application of exactly the theory which the speaker intends him to use to interpret this particular utterance. (The hearer's interpretation may be correct even if it is not completely correct. Correctness of interpretation allows for degrees. But I shall concentrate on the extreme case of complete correctness.)

Professor Davidson denies that what is needed for successful linguistic communication is an agreement in advance between speaker and hearer as to a language or system of interpretation. The prior theories of speaker and hearer may diverge. What really matters is that there be convergence at the critical point, at the actual occasion of the utterance. But even if the speaker's and hearer's prior theory were previously identical, this would not guarantee that the hearer can use it to correctly interpret the speaker's next utterance. For the speaker may make it very obvious by some feature of his next utterance that he now intends to be interpreted by the use of a different theory.

Again, let us briefly pause to clarify what is and isn't at issue. All that has been said so far concerns only the dimension of word-meaning, not the dimension of speaker's meaning. What the words used by the speaker in making his utterance mean in the speaker's mouth on that particular occasion, is what is at issue. This kind of meaning, Davidson claims, may change from one utterance to the next. Questions about speaker's meaning -e.g. if the speaker speaks ironically or metaphorically, if he refers to something different from what his words denote, etc. - such questions have nothing immediately to do with this claim. So we had better view

8 Ibid., p. 169.

9 Ibid., p. 169. 
interpretation as an enterprise which aims at determining two different things: first, what the speaker's words meant on a particular occasion; second, what the speaker meant on that occasion. By one and the same sentence, without a change of word-meaning, a speaker may mean different things on different occasions. But what is at issue in our discussion is word-meaning; in a series of utterances, the words used by a speaker may change their meanings.

Here is an example of such a change. A speaker in his first utterance speaks as usual, but in making his second utterance recognizably imitates somebody who uses these words with a different meaning. His first utterance is this: "Oh, I forgot to bring my Gameboy", and he utters this sentence in order to convey that he forgot a certain piece of game playing equipment. But then he puts on a particular accent which is characteristic of a certain French person who is famous for using the word "Gameboy". to refer to a Sony Walkman, and in this manner, says "Oh, and I forgot my Gameboy too" in order to convey that he also forgot his Walkman. So the same word, "Gameboy", has in two successive utterances two different meanings, without being used as an ambiguous word in either of these utterances. If the hearer is to interpret these utterances correctly, he has to switch interpretation manuals. The point can be emphasized by putting it this way: The speaker amuses himself with using two different languages, not with using one and the same language in two different ways.

Putting it that way may be somewhat misleading, though. Think of a case in which the hearer's passing theory compensates for a slip of the tongue on the part of the speaker. No allusion to a Frenchman's confusion is involved in the speaker's intentions. The speaker in our new example utters the sentence "Oh, I forgot to bring my Walkman", but he meant to use the word "Gameboy", and he intended to refer to his Gameboy. It just happened inadvertently that he uttered the word "Walkman". Here we have a case where the speaker intended to refer to a Gameboy and used the word "Walkman" to carry out this intention. But he did not, in the full normal sense of that phrase, intend, by using the word "Walkman", to refer to a Gameboy. Therefore he did not, in the full normal sense of that phrase, speak a language in which the word "Walkman" refers to Gameboys. Yet, to assign to the word "Walkman" the set of Gameboys is exactly the point of the passing theory which the hearer will apply if his interpretative attempt is to succeed. It would be odd to say that this passing theory describes a language which the speaker is speaking. The speaker was speaking English, even at that very moment when he fell victim to a slip of the tongue. He made a mistake in speaking English. He did not, on the spur of the moment, switch to a language such that his utterance was a flawless performance in that language. (Nor does Professor Davidson 
say he did.) I have mentioned this slip-of-the-tongue-case to point to three aspects of Professor Davidson's account: (a) it is a clear case where the passing theory does not describe a language spoken by anybody; (b) it is a case where Professor Davidson's dislike for speaking of linguistic errors and mistakes (at least as long as things go smoothly) is understandable, ${ }^{10}$ and (c) it is a case which happens all the time - more often than the clever allusion type of case mentioned before - but is not covered by the standard account.

VI.

Let's get back to the thread of the argument. The failure of the standard account on which Professor Davidson concentrates does not concern the dimension of speaker's meaning and is not to be located in the realm of pragmatics. Rather it has to do with what words mean and belongs to the realm of semantics. Davidson claims that there are cases in which what the very words mean in the speaker's mouth, on the occasion of the utterance, diverges from what these words usually mean, and that in such cases we are not confronted merely with a divergence of word meaning and speaker's meaning.

It cannot be denied, I think, that such phenomena occur. And I think one has to concede that speaker/hearers may be highly successful in interpreting each other's linguistic performances and yet not share a language in some way which would fit the standard account, as I have sketched it. But does that, by itself, show the standard account to be incorrect? Professor Davidson seems to think so. He seems to think that the standard account gives an essentially misleading picture of what is basically involved in successful linguistic communication.

Let me try to bring out more vividly what I take to be the bone of contention. The standard account presents speaker/hearers as highly inflexible with regard to word meaning. They are wedded to a certain truth theory. As for the speaker, this inflexibility involves sacrificing many forms of witticism; at worst, it makes the speaker a bore. As regards the hearer, much worse is in the offing. His inflexibility may lead him to serious misinterpretations, as soon as he is confronted with a linguistically deviant or flawed utterance.

${ }^{10}$ Cf. "A Nice Derangement of Epitaphs", loc.cit. p. 158 where Davidson states that "error or mistake of this kind ... is not philosophically interesting". As will become clear later, I think that Davidson is right about this particular kind of linguistic mishap. But this is not to say that the notion of a linguistic mistake is philosophically irrelevant. 
Professor Davidson's account, on the other hand, presents linguistic communication as a less dull line of business, even with regard to the dimension of word meaning. It is the playground for inventive and creative speakers and their mates. In such encounters, languages or truth theories are just tools designed to be handy for the occasion. That is their only point. There is no deep reason to insist on - or stick to - any particular one. On the contrary, such insistence would make it obvious that the very point of interpretation has not been understood.

Abelard, in his letters, distinguishes interpretation per usum from interpretation per ingenium. Davidson, like Abelard, has a penchant for ingenuity. (Yet, notice that Abelard was determined to interpret a passage from Ezekiel - wanting to find out what the prophet meant by his words whereas Davidson is trying to appreciate the literal meaning of ordinary people's words and sentences.) The standard account, on the other hand, wants us to stick to the usual with regard to word meaning and allows for ingenious deviation only within the dimension of speaker's meaning.

We must keep in mind that what is at issue, primarily, is literal wordmeaning. Everybody, even the adherent to the standard account, agrees that, first, outside the realm of literal meaning, ingenuity is often needed for understanding and that, secondly, word-meaning and speaker's meaning may fall apart so drastically that per usum interpretation won't do: it'll take some ingenuity to find out what the speaker's meaning was. (Grice and his secondary literature have provided us with beautiful examples for such ingenious interpretation.) But, let me repeat, Davidson's point is not about non-literal meaning or about speaker's meaning. Davidson's point is more dramatic: Even within the sphere of literal word-meaning, it may take per ingenium interpretation to get your next door neighbour right.

Consider this case. Somebody walks up to me and says "Harvey ist doof, aber nicht blöd". Let us assume that it is obvious that the German person saying this is fully serious. According to my prior theory, the sentence he has uttered is true if and only if Harvey is a blockhead, but not a dumbbell. The standard account nails me to this interpretation: Harvey is a blockhead, but not a dumbbell. - Now let us assume that blockheadedness and dumbbellness are the same. The standard account leaves no room for making slight adjustments to the truth theory. Whereas Professor Davidson's account allows me to swap the prior theory for a passing theory according to which "doof", as used by this speaker right now, means being loony in a puerile manner and "blöd" means being loony in an infantile manner.

The great advantage of flexible interpretation, it seems, is that it delivers appropriate sense in the first possible place. The speaker's words make no sense on the first approach, but they do make sense on the second one. According to our above assumption, the speaker was serious, literal and 
(trying to be) truthful in making his utterance, that is to say: he was not kidding me, he was not speaking metaphorically, ironically or what have you, and he was not lying (or attempting to lie). On that assumption, the following three things might be thought ${ }^{11}$ to coincide with regard to his utterance: what his words meant, what he meant by his words, and what he presented himself as believing. This trinity (of what the sentence meant, what the speaker meant to convey and what he presented himself as believing) can be kept together, only if we change truth theories during interpretation or if we consider the speaker to have absurd beliefs about Harvey's mental deficiencies. Professor Davidson's account allows us to change our minds about what the speaker's words mean on the occasion when they are spoken. We can put the blame on the prior theory and replace it, for this occasion, by a different one. The standard account, it seems, would force us to stick to our uniquely shared language and attribute a crazy belief to the speaker.

So it may seem that the standard account gets things wrong. It certainly gets things wrong when rigidly applied to such cases. I agree that the standard account, as stated here, is not universally applicable (or at least not unqualifiedly so), and also that Professor Davidson's account much more easily avoids the attribution of wildly strange beliefs.

But should the attribution of such beliefs be made as difficult as in Davidson's scheme of things? I don't think it should.

VII.

Before I turn to the less exegetical part of my paper, I want to pull these matters together and explain why I think that Davidson is not only mistaken about the relationship between speaker's meaning and literal meaning but already misconstrues the relationship between the following three concepts of meaning: conventional meaning, literal meaning and speaker's meaning.

The standard account, in effect, equates conventional meaning and literal meaning. According to the standard account, the literal meaning of a particular sentence, as used by the speaker on a particular occasion, is nothing but the meaning which is determined by the conventions ("the

11 But not by me. A further condition needs to be fulfilled: the speaker should be reflective about how he is putting things. Satisfaction of this further condition excludes several of Davidson's examples (e.g. all slips of the tongue and those of the malapropisms which are the result of momentary confusion rather than of lexical incompetence). So the argument sketched here to praise the advantages of flexible interpretation is not one I take to be really convincing. 
oath") to which the speaker is committed. Finding out the literal meaning is finding out the linguistic conventions to which the speaker is committed. Interpretation per usum is, typically (though not infallibly), the correct kind of interpretation when we are after literal meaning: When searching for the literal, we are necessarily searching for the conventional; and when searching for the conventional, we are, ceteris paribus, searching for the usual. (The conventional can, for brief stretches of time, fail to be the usual.)

Davidson's account recognizes these three aspects of meaning as distinct. But only two of them - namely literal meaning and speaker's meaning - are recognized as having philosophical significance. Conventional meaning is assimilated, by Davidson, to a highly insignificant concept indeed: a schoolma'am notion of proper or correct usage. ${ }^{12}$ It is hardly surprising that Davidson discards it, but it is surprising that he takes this to be the concept of conventional meaning which has been taken to be of philosophical importance by many philosophers - let me mention but a few: Wittgenstein, Ryle, Austin, Grice, Searle, Schiffer, Lewis, Bennett, von Savigny, and Dummett. Any philosophically significant concept of conventional meaning is simply ignored in Davidson's considerations.

Since the concept of literal meaning is, for Davidson, a philosophically interesting concept, it cannot coincide with his shallow concept of conventional meaning. This schoolma'am concept makes a difference only in the classtoom, when it comes to getting marks. It makes no difference in real life linguistic communication. Literal meaning, for Davidson, is interesting, because it does make such a difference. It plays a role in linguistic understanding, and this in turn, for Davidson, means: a role in radical interpretation. "All understanding of the speech of another involves radical interpretation", he claims. ${ }^{13}$ (Radical interpretation is interpretation per ingenium, or at least it is interpretation in which one must not blindly apply the usual standards.)

But when it comes to actually characterizing what literal meaning is, Davidson is either silent or perplexing. In "Communication and Convention" he presupposes, but never explicates, a distinction between literal meaning and what he calls ulterior purposes. ${ }^{14}$ This sounds, as Davidson acknowledges, reminiscent of J.L. Austin's illocution/perlocution-distinction. (Austin, by the way, famously thought that this distinction has to be drawn in terms of the concept of convention. ${ }^{15}$ ) But certainly the distinc-

\footnotetext{
${ }^{12}$ Cf. "Communication and Convention", loc. cit. p. 278; "A Nice Derangement of Epitaphs", loc. cit. p. 158; "The Structure and Content of Truth", loc. cit. p. 310.

13 Cf. "Radical Interpretation", in: Inquiries into Truth and Interpretation, p. 125.

14 Loc. cit., pp. $271 \mathrm{ff}$.

${ }^{15}$ Cf. J.L. Austin, How to Do Things with Words, Oxford 1975 (second edition), lectures $9 \mathrm{ff}$.
} 
tion between the illocutionary and the perlocutionary aspects of speech acts is not the same as that between literal sentence meaning and speaker's utterance meaning. Sentence meaning and word meaning, in Austin's scheme of things, belong clearly in the realm of the locutionary. So what we find in this paper, "Communication and Convention" is not very helpful for understanding what Davidson means by "literal meaning". ${ }^{16}$

In "A Nice Derangement of Epitaphs" Davidson is quite explicit about that topic. He redubs literal meaning as first meaning and says that "[r]oughly speaking, first meaning comes first in the order of interpretation". ${ }^{17}$ The first meaning of an uttered sentence is determined by the speaker's "self-referring" intention to be "interpreted in a certain way"; the speaker utters the sentence "with the intention of uttering words that will be interpreted by the [addressee] as true if and only if ...". ${ }^{18}$ But, again, this is not the usual sense (or any of the usual senses) of the term "literal meaning". ${ }^{19}$ Consider this example: $\mathrm{S}$ has arthritis and she is legally required to inform $A$ of all her diseases; she thinks that $A$ is so incompetent with regard to medical matters that he will interpret her utterance of "I have arthritis" as being true if and only if S has diabetes; and for some reason she prefers $A$ to think of her as having diabetes; so she utters the sentence "I have arthritis" with the intention of uttering words that will be interpreted by $\mathrm{A}$ as true if and only if she has diabetes; but certainly this is not the literal meaning of her words. It is not even the literal meaning of those words, as used by her on that special occasion. Therefore, so-called first meaning, whatever it is, is not literal meaning. In fact, it is so different from literal meaning that it cannot take its place in any appropriate account of linguistic meaning and communication.

So there is something profoundly mistaken in Davidson's view of linguistic communication. He gets off on the wrong foot, when he substitutes literal meaning by first meaning. No doubt; first meaning is a concept we need in a good account of linguistic communication. But we need it only for special cases like slips of the tongue or malapropisms. These are cases where the speaker makes a mistake with respect to the literal meaning of the sentence he utters. These are cases where the first meaning of the sentence, as uttered by him on that occasion, differs from

${ }^{16}$ Davidson, in this paper, is mainly concerned with a different question, namely whether sentence-meaning and speaker's meaning are connected by conventions. Davidson denies that. But this issue must not be confused with the question whether literal sentence meaning is somehow constituted by or dependent upon conventions.

17 Loc. cit., p. 159.

18 Ibid., p. 160.

${ }^{19}$ It is much more like a hybrid between what Grice calls utterer's occasion meaning and what he calls applied timeless sentence meaning. Cf. Paul Grice, Studies in the Way of Words, Cambridge, Mass. 1989, chapter 6. 
the literal meaning of the sentence. But Davidson unduly exaggerates the substantial insight that first meaning is a concept we need (for an adequate account of special cases) when he proposes to drop the concept of literal meaning and replace it by the concept of first meaning. This is to overgrice matters considerably. As a consequence, the role of ingenious interpretation is grossly exaggerated.

If we don't drop literal meaning, something like the following picture emerges: There are various dimensions of meaning, and Davidson has pointed to one dimension which has been neglected by many philosophers of language: a dimension which might be called compensatory word (or sentence) meaning. But I shall stick to Davidson's label: "first meaning". Consider again the case, mentioned above, where the speaker utters the sentence "I forgot to bring my Walkman", but means to say that he forgot to bring his Gameboy.

(1) What is the literal meaning of that sentence (in the common language)? - Answer: that sentence is true if and only if the speaker forgot to bring his Walkman. - Justification for this answer: The speaker means to be speaking regular English. (Hence there is a sense in which he is committed - in fact, a sense in which he may want to commit himself - to a certain standard of interpretation for his words, even if he - according to that standard - should get things wrong.) - Evidence for the existence of that dimension of meaning: We have in common usage phrases like "Strictly speaking, what he said was that ..." or "What he literally said was that ..." which do not allow, with regard to our example, for the truthyielding insertion of "he forgot to bring his Gameboy".

(2) What is the applied timeless meaning of that sentence (as uttered by the speaker) $?^{20}$ - This question does not apply (or has to be answered in the same way as the first question) since the sentence "I forgot to bring my Walkman" is not ambiguous.

(3) What is the first meaning of that sentence (as uttered by the speaker)? - Since the speaker has fallen victim to a slip of the tongue, this question applies. - The answer is: that sentence is true if and only if the speaker forgot to bring his Gameboy. - Justification for this answer: The speaker meant to be speaking regular English, and what he meant to be saying cannot be put, in regular English, by the words he actually used, but it can be put, in regular English, by using the sentence " $I$ forgot to bring my Gameboy". If the speaker afterwards remembers (or is informed about the fact) that the piece of equipment for playing video-games he intends to refer to, in the language he meant to be speaking, is not called a Walkman but a Gameboy, he will, ceteris paribus, acquire a disposition to use the word "Gameboy" instead of the word "Walkman". - Evidence

${ }^{20}$ For the concept of applied timeless meaning, cf. Paul Grice, loc.cit. 
for the existence of such a dimension of meaning: We have in common usage phrases like "(but) what he meant to say was that ..." which, with regard to our example, would have to be completed by "he forgot to bring his Gameboy" in order to yield a true report of what was going on.

(4) What is the speaker's meaning of that utterance? - Answer: This is not one question but a whole new family of questions about (a) illocutionary forces, (b) the prominent illocutionary force, if there is any, (c) the propositional content of the (prominent) illocutionary act the speaker performed in utteting this sentence, (d) the whole set of implicatures carried by various features of the utterance-in-context, and even (e) some aspects of perlocution, e.g. those perlocutionary effects which the speaker intended to bring about without concealing anything about how he intended to bring them about. But much more is at issue in the mystifying realm of speaker's meaning, e.g. the question whether there is some such thing as a "literal" (or "direct") utterance meaning which marks for an interpreter the starting point for inquiring into further things the speaker meant by his utterance. These are fascinating topics, but not ours right now. ${ }^{21}$

It would be a grave error to skip the first dimension of linguistic meaning: genuine literal sentence-meaning. For so-called first meaning dimension (3) - presupposes genuine literal sentence-meaning, in the way that any compensation for a mistake presupposes a standard of correctness. Davidson seems to indulge in building, ingeniously, a whole philosophy of radical interpretation around this grave error. "All understanding of the speech of another involves radical interpretation".

But in reality, radical or ingenious interpretation is only required when literal understanding fails or when it delivers undesirably poor results, e.g. nonsense. Among the things which trigger ingenious linguistic interpretation there are two which stand out: strange speech-sound and literal nonsense. Interpreting strange speech sound is also known as radical translation. Such translation, according to Quine and Davidson, is intrinsically inimical to attributing literal nonsense. Fine. One should be polite.

21 There is such an enormous amount of first-rate literature on these topics that I can mention here only a few outstanding contributions. First and foremost, of course, the two classics: J.L. Austin (How to Do Things with Words, Oxford 1962) and Paul Grice (Studies in the Way of Words, Cambridge, Mass. 1989). See also P.F. Strawson, "Intention and Convention in Speech Acts", Philosophical Review 73 (1964); John R. Searle, Speech Acts, Cambridge 1969, and Expression and Meaning, Cambridge 1979; David Lewis, Convention, Cambridge, Mass. 1969; Stephen Schiffer, Meaning, Oxford 1972; Jonathan Bennett, Linguistic Behaviour, Cambridge 1976; Brian Loar, Mind and Meaning, Cambridge 1981; Eike von Savigny, The Social Foundations of Meaning, Berlin / Heidelberg / New York 1988. 
Strangers never talk nonsense (in our presence). Okay. But how about my buddies? Doesn't familiarity breed the attributability of nonsense?

Davidson, it seems, has no sense for such semantical familiarity. He has a very radical-translation-oriented view of all linguistic communication. Semantically speaking, for him there are no buddies. It never goes without saying, for Davidson, that disquotation rules.

That's why Davidson misses the point of literal meaning. The common concept of literal meaning is designed to capture subtle semantic nuances which are only to be found in a disquotational milieu of linguistic communication. It is, among other things, designed exactly to capture a dimension of linguistic communication which allows for nonsense, absurdity, paradox and pointlessness. Literal meaning of a sentence is designed to be contrastable-come-what-may with what any individual speaker may achieve meaningwise. The literal meaning of what somebody has said, may be just rubbish. Still, what he meant to say, may be great. ${ }^{22}$

Davidson, it seems, unduly assimilates literal meaning to what has been meant to say. On his account, there is no place for a meaning-concept which lets in rubbish. But any nonsense-proof concept of meaning is not our concept of literal meaning. Even we ourselves talk nonsense occasionally. And we know it. Afterwards. Sometimes.

Dropping literal meaning in favour of first meaning not only blurs the distinction between what the speaker's very words mean (in his mouth) and what he means to say by them. It also leaves us helpless when it

22 And vice versa: Somebody may utter words the literal meaning of which is great, although what he meant to say was just dull or even rubbish. In such cases, the interpreter has to compensate for too good literal meaning by more credible first meaning. It is the opposite of charitable interpretation which is called for in such cases, let's call it nasty interpretation. Nasty interpretation is as difficult and philosophically challenging as any other kind of interpretation. I find it interesting, to a degree, that Davidson seems to have no sense for the bare necessities of nastiness in interpretation. Sometimes you know people too well. And it is as hard to ("nastily") interpret the words of somebody whom you know too well as it is to ("radically") interpret the words of somebody whom you know not well enough.

One may think of one's own words as a limiting case. Neither does one know oneself too well nor does one know oneself not well enough. Therefore, the escape toutes of nastiness and charity would be blocked whenever it came to self-interpretation. But it never can come to that. It never can come to interpreting oneself's words or thoughts at any present time. For in interpreting oneself, one would have to be stuck with literal interpretation. (There is no conceptual leeway for charity or nastiness in interpreting myself at a time. I can't be smarter or less smart, at that that time, than I am, at that time. And I know that, even if only implicitly, at that time.) Literal interpretation, in such a limiting case of the first person, would have to be disquotation. Disquotation is repetition (albeit on a different level). Repetition, on any level, is pointless. Therefore, self-interpretation would have to be pointless. Pointless interpretation is no genuine interpretation. So self-interpretation is no genuine interpretation. 
comes to describing cases like the one just mentioned: the case of the lady who says "I have arthritis" to her employer. She is not the victim of a slip of the tongue, a malapropism or what have you. On the contrary, she is in full command of the language she is speaking and is highly aware of how she is putting things. By courtesy of her very words' literal meaning she is not lying - although she willfully brings her addressee to acquire a belief she knows to be mistaken. She is the perpetrator of an act of misleading her addressee, and she performs this act by using a sentence.

But one must not call her a liar. Dropping literal meaning in favour of first meaning makes it hard to account for that distinction (between a liar and a lucky misleader) and for the difference it makes in judging, with regard to such cases, who is to blame for what. Furthermore, dropping literal meaning in favor of first meaning deprives us of the conceptual means needed to account for the fact that the lady's success was not achieved in a fully normal act of successful linguistic communication, but in an act which was in a way deficient, deviant and devious.

Davidson seems to want to dismiss all these fine nuances as not pertaining to the very idea of linguistic communication. Well, what is the very idea of linguistic communication, anyway? Communication by natural public languages like Italian, Chinese, English, Spanish, Welsh, Cornish etc., as they are spoken by their respective speakers, are our best clue. All these cases of linguistic communication involve, I assume, the distinction between lying and willfully-misleading-by-using-a-true-sentence. The burden of proof is on Davidson's side. So far, he has given us no reason to think that there is a philosophically significant concept of linguistic communication which does not require genuine literal meaning. And first meaning is not genuine literal meaning.

\section{VIII.}

There seems to remain a problem, as I have just presented things. One and the same sentence has been attributed divergent truth conditions in (1) and (3), although it was claimed, in (2), that this sentence is not ambiguous. How could that be?

One possible answer is this: The two attributions do not have the same subject of attribution. Sentences-of-a-given-language are (potentially) different from sentences-as-used-by-speakers. Sentences are essentially meaningful things, and there are various ways of blowing propositional content into types of vocal noise or into strings of letters. Languages are very abstract and pretty stable entities, a particular language may blow one way; whereas speakers are very concrete and highly capricious entities, and even a speaker of this particular language may blow another way. 
What makes things so difficult is this: it is hard to tell which way the wind blows, primarily. There is still the same old Humpty Dumpty question: "which is to be master". Any answer to Humpty Dumpty's profound question must acknowledge both: both the master who primarily means and the servant who must mean as the master does. Davidson is a good Gricean, he says: in the last analysis, speaker is master, language is servant. (Up to this point, I am a good Gricean myself, by the way.) But Davidson overdoes being a good Gricean, when he says: in the ultimate analysis, "there is no such thing as a language". Davidson, in effect, claims that speaker's meaning wins by default. But this is absurd.

Davidson over-grices linguistic meaning to the point where language vanishes (at least "if language is like anything what many philosophers and linguists have supposed"). In the following, I will try to convince (or persuade) right-thinking Davidsonians that shared languages (like many philosophers and linguists have supposed) exist and that this is a fact of considerable philosophical significance. Shared languages exist. Or else interpretation - radical and ingenious or otherwise - could not be objective. Or so I shall argue in the rest of this paper.

IX.

Linguistic communication is a special sort of non-natural communication. Any attempt at manifestly having a specific impact on somebody else's cognitive attitudes may be called an attempt at communication. In cases of non-natural communication, vehicles of meaning-transport are employed which are not natural signs of the meaning they carry. Linguistic communication stands out from other non-natural communication by the fact that the vehicles employed belong to a system of semantically interdependent items. ${ }^{23}$ Natural languages and their sentences yield the paradigm for such a system of semantically interdependent vehicles of meaning transport. Here, in the case of a natural language, speaking of semantical interdependence has a particularly clear sense. For a complete semantical description of the whole system must break up the meaning vehicles in parts and it must confer semantical values to these parts. The semantical interdependence among the meaning-transporting vehicles amounts to each vehicle's consisting of meaningful parts which occur with the same semantical value in other vehicles.

${ }^{23}$ There is another wide spread explication of the philosophers' term "linguistic communication" which has it that the system of meaningful items be conventionally established. I shall leave that aside. 
What meaningful parts? Things get philosophically interesting as soon as the meaningful parts are smaller than sentences. The kind of potentially infinite complexity which is dealt with in the propositional calculus is farfetched, invented and philosophically pointless. The interesting kind of complexity which I have in mind comes only with quantifiers, and other iterative adjectives and adverbs. The potentially infinite complexity which is involved already in a systematic rendering of the relation between "It's raining and it's raining" and "It's raining and it's raining and it's raining" is not what $I$ have in mind. What I have in mind is the complexity necessarily involved in any attempt to systematically specify the semantical relations between pairs of sentences like "I am very sorry" and "I am very, very sorry", or "Harvey is crazy" and "Harvey is crazy enough to try to strike up a friendship with a crocodile". My sortowfulness and Harvey's craziness can be described, in an interesting language, in potentially infinite ways which are semantically distinct but interdependent. When, in the following, I speak of indefinite complexity, forget about sentential connectives and always think of the second kind of semantical complexity and interdependence.

In this respect, linguistic communication is different from what might be called phrase book communication. ${ }^{24}$ In phrase book communication, the utterance types (the "sentences") envisaged are finite. At least in principle, a complete semantical description of a phrase-book-communication-system can do without assuming semantical interdependence. When it comes to giving an account of the mnemotechnical details of mastering such a system, that system might turn out to be so rich that only a building block description is psychologically credible. But the psychology of human memory is not of primary interest here. The line I want to draw is semantical. It's the line between a phrase book, as rich as you please, on the one hand, and a (compositional) truth theory ${ }^{25}$ on the other hand.

The difference is this: When I go to a foreign land with a phrase book in my hand, I am not equipped to attribute to speakers of that language (very) specific beliefs. There is this one entry in my book about present rain which assigns to the foreign phrase "Ogoulobogoulo" the phrase "It's raining". No distinction between a sprinkle and drenching rain to be found in that book. So when I sit there, abroad, with no access to the weather, and somebody utters "Ogoulobogoulo", I can't conclude anyhing very

24 What I have in mind here is usually called communication by use of a signalling language, but, in this context, I want to avoid the by now loaded terms "language" and "linguistic". A phrase book is a vehicle-to-vehicle assignment between two systems of non-natural communication.

25 In what follows, when I shall be speaking of a truth theory, I shall always mean a compositional semantics for a language which contains infinitely many sentences without sentential connectives. 
specific. Neither about the weather, nor about the utterer's beliefs about the weather. At home, in my language (which is more than a phrase book communication system), the whole spectrum ranging from exquisite sprinkles to intimidating torrents of rain would be awaiting me.

To put it differently: the concept of meaning which is applied in phrase book semantics is about a semantical magnitude which comes with a discrete scale; the concept of meaning which is applied in truth theoretical semantics is about a semantical magnitude which comes with a continuous scale.

Phrase books do not allow for the attribution of arbitrarily specific beliefs. In between the covers of a phrase book, there is a limit of specificity. And such a limit is alien to the spirit and the letter of a truth theory. For communication based on a truth theory essentially involves the possibility of attributing arbitrarily specific beliefs. Otherwise, if only beliefs of essentially limited specificity were involved, communication could be based, in semantic principle - even if not in psychological detail -, on a phrase book basis. Truth theoretical semantics is psychologically demanding.

There is something incoherent about the idea that successful communication may take place between a speaker who operates on a truth theoretical basis and a hearer who applies a phrase book (and no further semantical aids). In fact, a position which may be called truth theoretical solipsism is untenable, i. e. the idea that in communicating with others, I could apply my potential of making indefinitely many and arbitratily fine semantic distinctions without there being anyone else around with whom this potential could be shared. The idea of me being the only one who has a truth theory, all the rest of the speaking and interpreting world living on a phrase book basis is self-refuting. If I am prepared, in principle, to make infinitely many and indefinitely fine distinctions with regard to verbal expressions of what I believe, then I must assume that somebody else is prepared to do the same. There would be no conceptual space for my successful communication if there were just one truth theory (uniquely "instantiated" in my linguistic behaviour) within a sea of phrase book semantics.

If I were the sole competent speaker of that unique language, I could never hope to be understood completely by anybody else. My meanings simply would be too specific. Even my simple meanings would be too specific. For the problem here is not only that highly select meanings could not be communicated, like when I mean by one of my sentential utterances that we are having the most delightful pluviosity since last fall. The problem is present and pressing already with the most simple sentences of my language like "It is raining", because that sentence has a meaning distinct from indefinitely many other sentences to which it stands in 
semantical contrast. Even this pedestrian sentence marks a point in an indefinitely articulate network, and therefore its meaning cannot be given, completely, within the limits of a system that has no genuine semantical interdependence among its finitely many meaning vehicles.

On the other hand, if I were the hearer (in unique possession of a truth theory), I could not but over-interpret my speakers with regard to specificity. A phrase book speaker can only give imperfect expression to his beliefs. Or, maybe, he can give only expression to his imperfect quasibelief-states. Anyway. It would be never be completely correct to render the content of his verbal signals by any one of my sentences. Strictly speaking, "Ogoulobogoulo", if it belongs with proper phrase book semantics, does not mean that it is raining, simply because the system to which it belongs lacks semantical interdependence. There is no sentence of a language, in the strict sense of "(interesting) language" mentioned above, which could specify what exactly such a verbal signal means. Languages proper, on the one hand, and phrase book communication systems, on the other, are, strictly speaking, semantically incommensurable.

$\mathrm{X}$.

What marks off linguistic communication from other forms of non-natural communication is this feature: the beliefs expressed and the meanings conveyed have a degree of specificity which is indefinite. (It always makes sense to ask: "Does this vehicle mean exactly that, e.g., it is raining? Or does it mean something slightly different, e.g. that it is raining considerably?" ${ }^{26}$ Hence, as I have just argued, complete understanding in linguistic

26 Semantically speaking, there is a difference between "Harvey is very cute" and "Harvey is very, very cute", and, again, between this and "Harvey is very, very, very cute" and so on. Psychologically speaking, any such difference will be shading into non-existence pretty soon. We find it affected to make a distinction between the application of $\mathrm{n}$ and of $n+1$ iterated occurrences of the word "very" for $n>2$, we find it pointless for $n>3$, and soon thereafter we shall find it impolite, ridiculous, inacceptable and, from some value of $\mathrm{n}$ on, impossible. - Examples like these raise interesting questions about the status of sentence-meanings. If we find it humanly impossible to grasp a difference in meaning between two given sentences but feel, as truth-theorists of meaning, obliged to acknowledge some such difference - what should we, then, conclude? Should we be sensualistic about these matters, and accept only differences in meaning which we can, as it were, feel? Or should we approach such phenomena like a scientific realist and accept the existence of "imperceivable" semantical differences in the same manner as we accept, without batting an eyelid, the existence of imperceivable quarks? Semantic sensualism clearly has a tendency to undermine the truth theoretical approach to the semantics of natural languages. Scientific tealism applied to these issues has a reificational tendency which is certainly unattractive for a good Davidsonian. These are hard problems. But since Davidson ignores them, I shall, for the present purposes, keep up my attitude of naiveté: the semantic distinction between phrase books and truth theories is unassailable. 
communication presupposes that speaker and hearer have (and recognize each other to be having) a capability of expressing beliefs which essentially have an indefinitely high degree of specificity.

Our capability of having and expressing indefinitely specific propositional attitudes is of fundamental philosophical importance. Not only for the philosophy of language, but for many central areas in philosophy. In ancient days, human beings were characterized by philosophers as creatures which have "logos" or "ratio". Within the last hundred years or so, it has become increasingly manifest that one of the aspects that makes "logos" or "ratio" such a difficult topic is exactly this feature of arbitrarily high specificity of propositional attitudes.

These issues are surrounded by fascinating and intriguing questions, for example "How is this capability of indefinite specificity acquired and applied?". I shall try to concentrate on a more modest topic, namely: Assuming a realist attitude towards the concept of belief, how can we make sense of the objectivity of ordinary belief-attributions? By an ordinary belief-attribution, I mean an ordinary case in which a belief-predicate like "believes that it is raining" or "believes that Harvey is a blockhead" is applied to somebody. And by the objectivity of a statement or judgement, I mean basically all that goes with its intersubjectively homogeneous cognitive evaluation, in particular all that is presupposed by the possibility that the (factual) statement or judgement which has been made by one person is definitively corrected by somebody else.

I have called the question about the objectivity of belief-attributions a relatively modest topic because it avoids the more fundamental question whether such attributions are ever objectively true. In the following, I shall presuppose that the answer to that more fundamental question is: Yes, ordinary belief-attributions are sometimes objectively true. It has been argued, for example by Quine and Stich, that this is not so. ${ }^{27}$ And though I will not try to answer their arguments, let me just point out that their subjectivist accounts of belief-attribution are based on the assumption that it makes no objective sense to speak of two people's sharing a language. This has to do, I assume, with the fact that both Quine and Stich have a tendency to identify what is objective with what can be captured in a naturalist description of the world. Moreover, both seem to take it for granted that belief-states (if there were such things) would have to be individuated individualistically or non-externally.

In presupposing the correctness of an objectivist account of beliefattribution, I do deny the appropriateness of at least one of those standards of objectivity. In fact, I deny the naturalist standard. My attitude towards

${ }^{27}$ Cf. Willard Van O. Quine, Word and Object, Cambridge, Mass. 1960, especially 45; Stephen Stich, From Folk Psycbology to Cognitive Science, Cambridge, Mass. 1983, Part I. 
individualism (or internalism) is more favourable but I won't go into that here. ${ }^{28}$ Just take me to be denying any kind of (reductivist) naturalism, including internalist naturalism.

XI.

In giving a philosophical account of a concept it is of primary importance to account for simple uncontroversial cases, if there are any, to which the concept clearly applies. So in what follows, I shall restrict myself to simple attributions of belief-properties which are obviously true, if any such attributions are, and I shall inquire into the nature of their objectivity.

I have no definition for what is an obvious truth. And I am not extremely confident that the following sufficient condition is very helpful, but at least it will give you an idea of what $I$ am aiming at in the next sections. I want to call an attribution of a property $F$ to an entity $x$ obviously true if there is a condition (or set of conditions) $\mathrm{C}$, such that (1) something's satisfying $C$ is evidence of the best possible kind for its being $F$, although (2) something's satisfying $C$ does not entail that it is $F$, and (3) $x$ satisfies C. - Here is an example. It is obviously true that Harvey is not in my study, if Harvey satisfies the following condition: he is in my office which is more than two miles away from my study. (There may be possible worlds in which Harvey somehow manages to be in both these distant places at the same time, and therefore his presence in the office does not entail his absence from the study. But as things stand his presence in the office is still evidence of the best possible kind for his absence from the study.)

XII.

And here comes my claim: The only criteria we have at hand in order to establish the obvious truth of belief-attributions involve the idea of a shared language. It is this wherein I scent the philosophical significance of a shared language (or should I say: the philosophical significance of the idea of a shared language). Any belief-attribution which is obviously true presupposes the idea of a shared language. ${ }^{29}$

${ }^{28}$ I have gone into that, at deplorable length, in a paper entitled "Genau dieselbe Überzeugung" (Intentionalität und Versteben, Forum für Pbilosopbie Bad Homburg (ed.), Frankfurt 1990). I still think that individualism is feasible, when it comes to trying out a science of the human mind. But my provisos and qualifications have piled up in between.

${ }_{29}$ There are passages to be found in Davidson's work where he sounds receptive to this idea. In "True to the Facts" he remarks: 
Let me give you another example of an obvious truth: Jill believes that Harvey is a blockhead. Here is why this is obviously true. First, because Jill satisfies the condition of being a normal, adult, competent speaker of American English who has seriously, reflectively and truthfully uttered the sentence "Harvey is a blockhead", thereby referring to Harvey. Second, because Jill's satisfying this condition is evidence of the best possible kind of her believing that Harvey is a blockhead.

And while we are at it, let me give you a third example for a candidate of an obvious truth. Daniela believes that Harvey is crazy. She satisfies the condition of being a normal, adult, competent speaker of Italian who has seriously, reflectively and truthfully uttered the sentence "Harvey e pazzo", thereby referring to Harvey. And Daniela's satisfying this condition is evidence of the best possible kind of the fact that she believes that Harvey is crazy. - Well, on second thoughts, is that really evidence of the best possible kind? I don't know enough Italian and American English, so I can't say. But I can offer another reason for taking it to be obviously true that Daniela believes that Harvey is crazy. First, Daniela is a normal, adult and competent speaker of some natural language. And - that's still the first point - if she were a normal, adult, competent speaker of our natural language (i. e., for the purposes of this paper, American English), she would answer our question "Is Harvey crazy?", in that very wording, with an unqualified affirmation, therein being serious, reflective and truthful. And her satisfying this counterfactual condition is also the right kind of evidence: best possible evidence for the claim that she believes Harvey to be crazy. Certainly it is not evidence which is easy to get. It may be a tough question whether Daniela (who is not a competent speaker of American English) in fact satisfies this counterfactual condition. But if she does, everything is as plain sailing as in Jill's case.

Daniela's case invites for a general criterion of belief-attribution. "Somebody believes that so-and-so if the following condition holds: If he or she were a normal, adult, competent speaker of American English, he or she would -if asked (in American English) whether so-and-so- answer

What we can hope to make sense of, I think, is the idea of a sentence in another tongue being the translation of a sentence of English. ... we seem tequired to understand what somebody else would mean by a sentence of our language if he spoke our language. But difficult as this concept is, it is hard to see how communication can exist without it. (Inquiries into Truth and Interpretation, p. 53; bold italics mine)

Decidedly, this could serve as the motto for the rest of my paper. Of course, I have boldly italicized the phrase "our language" in that quotation, whereas Davidson then hasn't and nowadays wouldn't. 
with an unqualified affirmation, therein being serious, reflective and truthful." This is a sufficient condition for ascribing beliefs to people. 30

There are plenty of cases where this criterion is not applicable. It is a general criterion, not a universal one. But we have nothing better in our sight and nothing as good at hand which could serve as a criterion for the obvious truth of belief-attributions.

This criterion applies in the first place to actual speakers of our language, i. e. the language which is used in making the attribution. It applies by speculative extension to all other candidates (i. e. possible speakers of our language). For better or worse, it fails to apply to impossible speakers of our language, like e.g. computers, flies, dogs, lions, dolphins and maybe even some coffeehouse intellectuals. This is not to say that they don't have beliefs. It is just to leave open the question how the attribution of a specific belief to them could be warranted.

Our criterion holds true under translation. A German version of it reads as follows: "Jemand glaubt, daß so-und-so, falls die folgende Bedingung erfüllt ist: Wäre sie oder er ein normaler, erwachsener, kompetenter Sprecher des Deutschen, dann würde sie oder er - vor die Frage gestellt, ob so-und-so - uneingeschränkt bejahend antworten und wäre dabei ernsthaft, bedacht und aufrichtig". As you will have noticed, in its German version, the criterion turns to competent speakers of German. In its Xese version, it'll concentrate on competence in Xese. The criterion is lingually egocentric, or - if you can tolerate a bit of lingo - it is lingocentric.

XIII.

Is lingocentricity not dissonant with objectivity? It certainly is dissonant with objectivity if the language in question were characterized as something subjective. A lingocentric criterion of belief-attribution would be inac-

${ }^{30}$ By the way, as long as we restrict ourselves to this criterion we need not be afraid of certain otherwise impending puzzles. Think of Kripke's Pierre as a normal, adult, competent speaker of American English who happens to be speaking French also. If we asked Pierre (in American English) whether London is ugly, he would say "Yes"; if we asked him (again in this language) whether London is pretty, he would in all desirable consistency say "No". If we asked him "Is London both ugly and pretty?", he would say "Of course not". No puzzle in the offing so far. And our criterion does not reach farther.

If we think of Pierre as a normal, adult, competent speaker of French, we should switch to a French version of our criterion. Again, the results would not be puzzling. Our criterion is puzzle-proof in any version.

So the question arises if this criterion solves, in a sense, the Kripkean puzzles or if it rather leaves something important out. I think that this is an interesting question and certainly don't want to try to answer it in a footnote. 
ceptable as a way of capturing the objectivity of belief-attributions if it involved reference to my language essentially. If this phrase, "my language", were to imply that I can do within the realm of my language whatever pleases me - and that I can do it without being responsible to any kind of criticism - then bringing in my language could be of no help in objectifying belief-attributions. (Otherwise, I could rule, e.g., that in my language the sentences "It's raining" and "It's raining considerably" are synonymous. But I cannot rule such a thing for our language, or for English, or for any shared language.)

Therefore, bringing in lingocentricity has to be construed as relativization to shared languages. And this makes it desirable to have an account of what it is, for two or more persons, to be competent in the same language. Professor Davidson does not believe in the philosophical significance of a shared language, so probably he disagrees with my lingocentric account of belief-attribution. For this account brings in the idea of a shared language centrally. And if this is - as I claim - the only account we have of making sense of the objectivity of obviously true attributions of indefinitely specific beliefs, then the idea of a shared language takes on the flavour of essentiality. And anything with that flavour smells of philosophical significance.

XIV.

Or is it just bad smell? Certainly to the nose of an adherent to internalist naturalism. Quine, Stich and others are right: there are no prospects for an internalist naturalist account of what it is, for a group of individuals, to be competent in the same language. Internalism leads to searching for the language spoken by an individual within his or her body-limits. The internalist has a tendency to think of a shared language as something miraculous. How wondrous that two semantic painters should depict the infinite universe of meanings in exactly the same way! Their perspectives and experiences must be so very different!

Naturalism leads to neglecting or playing down the whole dimension of normativity. The naturalist has a tendency to think of a shared language as an invention of the theorist. After all, there are only finitely many patterns of firing neurons, and such patterns are - in the last analysiswhere all cognitive action is. Hence a phrase book account should do, in principle. At least "if we are limning the true and ultimate structure of reality" 31 , there is no good answer to the question "what are languages, and when do they count as identical or distinct". ${ }^{32}$

31 Willard V. O. Quine, Word and Object, Cambridge, Mass. 1960, p. 221.

32 Ibid., p. 214. 
What's normativity got to do with all that?

It's a complicated story.

In my closing remarks I shall just hint at a few highlights of the plot. But before I turn to that, let me briefly take stock. Contrary to what Professor Davidson holds, I take it to be a problem of great philosophical importance to give an account of what it is for two people to share a language. The concept of a shared language comes in essentially as soon as we want to account for the objectivity of obviously true attributions of arbitrarily specific beliefs. Expressing such beliefs and recognizing such beliefs as being expressed is a hallmark of linguistic communication.

So the analytical order of my argument, meant to persuade the Davidsonian, up to this point is this. [1] We want to give a philosophical account of successful linguistic communication. [2] It is distinctive of linguistic communication, successful or not, that belief-attributions of indefinite specificity are involved. [3] Such belief-attributions are, at least sometimes, objectively true or objectively false. Objectivity befits in particular those obviously true belief-attributions which are based on evidence concerning language-use. (In such cases, the specific belief is determined by way of determining exactly what has been expressed, in making a linguistic utterance, as being believed.) Hence [4] we want a philosophical account of the objectivity of such belief attributions. [5] A naturalist individualistic view does not yield such an account. [6] The only starting point in sight for an account of such belief attributions refers us to (the concept of) a shared language. Hence [7] the concept of a shared language is of philosophical significance (provided that an account of successful linguistic communication is of such significance).

XV.

Given that a naturalist individualistic position fails for our purposes, how could we hope to give a credible account of a shared language? It is at this point that, with no aspiration towards originality, I want to bring in normativity as the theoretical saviour. The concept of normativity I want to bring in, at this point, is a surprise packet. It contains glamorous items like rights and duties, commitments to (and impositions of) truth conditions, acceptations of corrections, and intersubjective agreement. On closer inspection, it may turn out to be Pandora's box. But let's give it a try.

And in doing so, let's leave aside all troublesome features of languages like ambiguity, indexicality and what have you. Forget even about troublesome features of human communicators such as confusion, rashness, thoughtlessness, playfulness, unseriousness etc. Leaving all this out for a 
moment is no cheating. It just helps us to concentrate on the basic problem, namely: giving an account of what it is for two speakers to share one language. To make things easy, we'll deal with boringly virtuous speakers and boringly poor languages. We are approaching the holy places of language use: the sanctuaries of homophonous interpretation.

\section{XVI.}

Any account of what a shared language is must involve some theoretical device which delivers assignment of truth conditions to an infinity of sentences, regardless of who of the language-sharers uses any of these sentences. This theoretical device should be insensitive to the psychological peculiarities of individual speakers and just capture their semantic joint possession. One such device is the concept of a speech community.

Here is an off hand definition: Two speakers belong to the same (homogeneous) speech community, if their utterances are treated (and are to be treated) equally with regard to resulting rights and duties. That is to say, in a speech community, speakers are treated semantically without respect of person. Pure semantics have to do with what you achieve purely linguistically, as just another speaker of a given language. Therefore, by uttering the sentence "It is raining", all speakers of the same (homogeneous) speech community commit themselves to be expressing exactly the same truth condition. And here comes the important tag: even if they bave different ideas of what rain is. ${ }^{33}$ Insofar as truth conditions of utterances capture functional roles of their utterers in the network of social rights and duties, attributing truth conditions has little and only indirectly to do with individualist psychology.

XVII.

Think of betting. A few days ago, I bet Harvey five bucks that it was raining. Harvey's very words were "It's not raining", I bet against him. We went out to check the weather. It was raining. But Harvey said, "That's no rain, dude. That's just light drizzle. Gimme the money." Harvey would never lie to me. So by his utterance he really meant to be accepting a bet the winning conditions of which were satisfied by the actual weather. But he had accepted a bet, the exact wording of which was "It's not raining".

33 That's certainly Frege's idea about these matters. Probably, it's the Tractatus-Wittgenstein's idea. It's pretty obvious that even the late Wittgenstein cherished this idea (if you do not insist on trutb-conditions). 
He was committed to winning conditions different from those he thought he was committed to. It was raining. Losing conditions of Harvey's bet obtained. According to the relevant truth theory, Harvey had bet that it was not raining. So he lost. He had to pay me five bucks. He payed.

Why was Harvey committed to those winning conditions? Because he stuck around for a sufficiently long time with the relevant bunch of people to have achieved the status of a competent bettor. They imposed their winning conditions on his English sounding bets with them. He accepted that. They all did that to each other. They still do it. That's what makes them having a shared communication system for betting.

The essential point is not that a communication system for betting be shared between any two bettors. Such a system would make betting things particularly easy. But the kind of objectivity which is essential for betting can be established without such a shared system of verbal or gestural signs. What counts is that the two bettors commit themselves to the same winning/losing-conditions, by whatever signs this identical commitment is achieved. (The one bettor may have used the sound "hutchee", the other may have used "hutchoo" when they betted. With a little help from their respective friends they may be committed to accept any case of sneezing as a relevant betting conditions.)

XVIII.

Among other things a language is a system which allows its speakers to have arbitrarily specific bets. Many of the assertive uses of linguistic means can be profitably viewed in close analogy to bets. (Something certainly needs to be said about what the stake is, and in which sense the hearer of an assertion resembles somebody who takes up a bet. But let that go.)

The whole institution of betting presupposes the concept of two people's being committed to the same winning conditions by the same words. It is of the essence for a bet to take place that the two bettors share a commitment to the same conditions even if they have different ideas of what these conditions are.

But who fixes those conditions they are committed to? If no quartel comes up about who has won, everything goes smoothly. In case of conflict, an "impartial and well-informed spectator" ${ }^{34}$ a "judge" 35 or a "group" 36 comes in handy. Of course, he or she or they may be hard to

34 Adam Smith, The Theory of Moral Sentiments, London 1759, section 2, chapter 1.

35 J.L. Austin, How to Do Things with Words, Oxford 1975 (second edition), p. 122.

${ }^{36}$ Eike von Savigny, The Social Foundations of Meaning, Berlin / Heidelberg / New York 1988, chapter 2. 
find. But it is even harder to have a bet without accepting the idea that a possibly ensuing quarrel could be settled in this mannet.

Even if the analogy between betting and linguistic communication may be a bit strained, I think it points to an important aspect. Let me try to bring out this point by adding another twist. Consider the question: Where exactly does a shared language come into the picture? As I said before, I think that Professor Davidson is fully right in claiming that linguistic communication can be successful even if speaker and interpreter do not share a language. The idea of a shared language lurks in the background of linguistic communication. It concerns the interpreter's linguistic competence of his language, i. e. the language in which his interpretation is expressed. It is this language which the interpreter has to share with other people (not necessarily with his interpretandus). It must be possible for him to make mistakes in his interpretative attempt. It must be possible that such mistakes could be corrected by others. But such corrections could only be made by somebody who is competent in the interpreter's language. (It would be irrational or unreasonable to accept criticism which is assumed to be incompetent.) In this sense, linguistic communication presupposes the idea of a shared language. A shared language is needed, not so much as a condition of interpretative success but rather as a precondition of the objectivity to which we aspire in interpretation. ${ }^{37}$

37 Thanks to the members of the seminar on problems in analytic philosophy at the university of Munich, and to Donald Davidson, Hanjo Glock, Brian Loar, and Bernhard Thöle for comments on earlier versions of this paper. Special thanks to Katia Saporiti and Stephen Schiffer. Sebastian Edwards, Margot Magowan and Mark Helme were kind enough to check and improve my English. 